\title{
Profiling of Volatile Compounds with Characteristic Odors in Bambusa oldhamii Shoots from Taiwan
}

\author{
Minjay Chung, ${ }^{a}$ Sensung Cheng, ${ }^{a}$ Chunya Lin, ${ }^{b}$ and Shangtzen Chang ${ }^{c}, *$ \\ This study focuses on volatile aromatic constituents extracted using solid- \\ phase microextraction (SPME) from underground and aboveground \\ Bambusa oldhamii shoots. Analysis was conducted using the extracts after \\ heating at various temperatures and for various durations. Results of gas \\ chromatography-mass spectrometry (GC-MS) revealed six SPME- \\ extracted volatile aromatic compounds in underground $B$. oldhamii shoots \\ and eleven in aboveground $B$. oldhamii shoots. Methyl salicylate with a \\ characteristic mint aroma and methoxy-phenyl oxime that gives a smell of \\ fresh shrimp and crabs are the main volatile compounds found in \\ underground and aboveground shoots of $B$. oldhamii, respectively. \\ Moreover, the two types of shoots tested also contain volatile compounds \\ including fatty acids: $n$-hexadecanoic acid (27.94\%) and aliphatic \\ aldehyde: trans-2-nonenal (16.31\%), respectively. The GC-MS analysis of \\ underground and aboveground $B$. oldhamii shoots steamed at $100{ }^{\circ} \mathrm{C}$ for \\ 60 min revealed $n$-hexadecanoic acid as the main fatty acid compound.
}

Keywords: Bamboo shoot; Bambusa oldhamii; Solid-phase microextraction (SPME); Gas chromatography-mass spectrometry (GC-MS)

Contact information: a: Experimental Forest, National Taiwan University, No. 12, Section 1, Chien-Shan Road, Chu-Shan, Nantou Hsien, 55750, Taiwan; b: Department of Wood Based Materials and Design, National Chiayi University, Chiayi City 60004, Taiwan; c: School of Forestry and Resource Conservation, National Taiwan University, Taipei 10617, Taiwan; *Corresponding author: peter@ntu.edu.tw

\section{INTRODUCTION}

Bamboo shoots, which are root sprouts protected inside bamboo sheaths, are the main by-products of bamboo forest cultivation. Asian cuisines have had a long history of bamboo shoot consumption. Not only are bamboo shoots delicious and crisp in texture, they are also natural and have nutritional benefits of being high in fiber and low in calories (Satya et al. 2010). Research conducted on bamboo forests showed a wide variety of bamboo shoots cultivated over a large area, with the four main types being Dendrocalamus latiflorus, Phyllostachys pubescens, P. makinoi, and Bambusa oldhamii (Lu 2001). Each type of bamboo shoot has its own distinctive flavor and texture, and local delicacies made from bamboo shoots have been developed in different regions of Taiwan. Thus, the harvest of shoots from $D$. latiflorus, $B$. oldhamii, and $B$. edulis has become central to the management of bamboo forest, indicating high utilitarian value of bamboo forests (Liese 1987). Among diverse bamboo types, $B$. oldhamii shoots are one of the most important summer crops of Taiwan. Besides being consumed as fresh food, $B$. oldhamii shoots can also be processed into dried or canned foods, with canned $B$. oldhamii shoots being the main variety to be exported. Hence, the culinary and economic value of B. oldhamii shoots merit attention (Tsai 2002).

In recent years, there has also been research regarding the health benefits of bamboo shoots. For example, D. latiflorus shoots are rich in antifungal proteins, such as 
dendrocinino and dendrocin, which are sources of natural phenolic antioxidants (Park and Jhon 2010). Additionally, the natural oils of bamboo shoots contain phytosterol, which not only helps to lower serum cholesterol but also possesses anti-inflammatory properties (Lu et al. 2011). Moreover, to promote the specialty of fermented bamboo shoots, Fu et al. (2002) explored further the aroma-active components and unique flavors of D. latiflorus. Among six edible bamboo shoot extracts obtained, Tsai (2002) found that the phenolic components in shoots of $D$. latiflorus and $B$. oldhamii have antibacterial properties. The above research findings indicate increasing attention being paid to the characteristics of various bamboo shoots in their applications to health and food products. Furthermore, upon comparison of two types of $P$. pubescens shoots, Chung et al. (2012) concluded that spring and winter shoots at room temperature contained different volatile compounds. Zhang et al. (2016) revealed that the intensity of bitterness and astringency, tannin content of aboveground $D$. latiflorus shoots were significantly higher than those shaded bamboo shoots. Cui et al. (2017) indicated that moso bamboo (P. edulis) buried in the soil, its flavor substances and spicy intensity are significantl1y different from those on the soil. The spicy intensity is inversely proportional to the boiling time. It can be confirmed that underground shoots and aboveground shoots have different flavors and compositions.

Extraction of chemically reactive compounds from phytoncides, essential oils, and other organic compounds from plants has been making rapid advances. Highly regarded by industrial professionals, the solid-phase microextraction (SPME) method can easily extract volatile compounds from woody fibers and leaves without the need for organic solvents (Steffen and Pawliszyn 1996; Chen et al. 2010). In view of such advantage of this extraction method and its wide applicability, this study utilizes SPME to extract volatile compounds from $B$. oldhamii shoots and analyzed their composition using gas chromatography-mass spectrometry (GC-MS) and gas chromatography coupled with flame-ionization detection (GC-FID). In addition to detecting aroma-active compounds of B. oldhamii shoots at ambient temperature, this research also examines the effects of heating temperature and steaming durations on volatile compounds of bamboo shoots. Findings of this study not only would shed further light on the characteristic of bamboo shoots, but also facilitate the promotion of specialty products from bamboo forests both for culinary use and health benefits.

\section{EXPERIMENTAL}

\section{Materials}

Two kinds of B. oldhamii shoots, including shoots buried in soil and those sprouted above soil, were obtained in July 2018 from the Shuili tract of the Experimental Forest (Nantou County, Taiwan), National Taiwan University. In general, the below-ground shoots were at an earlier physiological stage compared to the above-ground shoots. The underground shoots (UB) of $B$. oldhamii were of smaller size with base diameter ranging from $8 \mathrm{~cm}$ to $10 \mathrm{~cm}$. The aboveground shoots $(\mathrm{AB})$ of $B$. oldhamii were larger with base diameter ranging from $10 \mathrm{~cm}$ to $15 \mathrm{~cm}$. When harvested, the fresh bamboo shoots were washed and then stored in a sealed bag at $-80{ }^{\circ} \mathrm{C}$ without exposure to light prior to analysis. 


\section{Methods}

Treatment conditions

To examine the changes in composition and relative contents of volatile aroma constituents under different heating temperatures $\left(40{ }^{\circ} \mathrm{C}, 60^{\circ} \mathrm{C}\right.$, and $\left.100{ }^{\circ} \mathrm{C}\right)$ and durations (5 min, $30 \mathrm{~min}$, and $60 \mathrm{~min}$ ), volatile compounds present in B. oldhamii shoots were extracted using SPME.

\section{Extraction of volatile compounds by SPME}

The manual SPME device and $65-\mu \mathrm{m}$ polydimethylsiloxane-divinylbenzene (PDMS/DVB) fiber used in this study were purchased from Supelco Co. (Bellefonte, PA, USA). The PDMS/DVB fiber was conditioned as recommended by the manufacturer prior to the extraction. Fresh B. oldhamii shoots of $3 \mathrm{~g}$ in weight was placed a $20-\mathrm{mL}$ vial closed by a polytetrafluoroethene (PTFE)/silicone septum without any solvent, and then heated for $30 \mathrm{~min}$ in water baths of $25,40,60$, and $100{ }^{\circ} \mathrm{C}$.

The SPME fiber was then inserted into the vial and adsorbed the volatiles of $B$. oldhamii shoots in the headspace of the vial. The adsorption time of each extraction was held for $30 \mathrm{~min}$ at different temperatures and then desorbed at the gas chromatography (GC) inlet for $5 \mathrm{~min}$ at $230{ }^{\circ} \mathrm{C}$. Similarly, the samples were steamed at $100{ }^{\circ} \mathrm{C}$ for various durations before SPME extraction for further analysis.

\section{GC-MS and GC-FID analyses}

Volatile compounds present in B. oldhamii shoots were analyzed using a Trace GC PoLaris Q mass (ion source temperature $230{ }^{\circ} \mathrm{C}, 70 \mathrm{eV}$ ) instrument (Thermo Electron Corporation, Waltham, MA, USA) equipped with a DB-5ms capillary column (Crossbond $5 \%$ phenyl methylpolysiloxane with a length of $30 \mathrm{~m}$, diameter of $0.25 \mathrm{~mm}$, and film thickness of $0.25 \mu \mathrm{m}$. The oven temperature was held at $40{ }^{\circ} \mathrm{C}$ for $4 \mathrm{~min}$, then programmed to increase from 40 to $230{ }^{\circ} \mathrm{C}$ at a rate of $4{ }^{\circ} \mathrm{C} / \mathrm{min}$ and held for $5 \mathrm{~min}$. Other parameters included injector temperature, $230{ }^{\circ} \mathrm{C}$; carrier gas, helium at a flow rate of $1 \mathrm{~mL} / \mathrm{min}$; split ratio, 1:30; and scan range, 50 to $400 \mathrm{amu}$.

Each extraction took approximately $47 \mathrm{~min}$. Identification of major compounds of B. oldhamii shoots was confirmed by comparison against standards, by spiking, and on the basis of their mass spectral fragmentation pattern using the Wiley 7.0 and National Institute of Standards and Technology (NIST) mass spectral search program (version 2.0f) with Xcalibur data system (NIST 2020 MS 2.0, Thermo Fisher Scientific Inc., Waltham, MA, USA). Quantification was performed by percentage peak area calculations using the GCFID. In addition, the Kovats index, given by the equation below, was also calculated (Eq. $1)$,

$$
\mathrm{KI}=100 N+100 \frac{\log t^{\prime} \mathrm{R}(\mathrm{X})-\log t^{\prime} \mathrm{R}(N)}{\log t^{\prime} \mathrm{R}(N+1)-\log t^{\prime} \mathrm{R}(N)}
$$

where $t^{\prime} \mathrm{R}(N)$ and $t_{\mathrm{R}(N+1)}^{\prime}$ are the adjusted retention time for $N$ and $N+1$ carbon atoms in $n$ alkanes, $t^{\prime} \mathrm{R}(\mathrm{X})$ is the adjusted retention time for an unknown compound $\mathrm{X}$, and $t^{\prime}{ }_{\mathrm{R}(\mathrm{X})}$ should fall between $t^{\prime}{ }_{\mathrm{R}(N)}$ and $t^{\prime} \mathrm{R}(N+1)$. 


\section{RESULTS AND DISCUSSION}

\section{Volatile Compounds of B. oldhamii Shoots at Ambient Temperature}

Figure 1 displays the volatile aromatic compounds released from $\mathrm{UB}$ and $\mathrm{AB}$ from B. oldhamii and their relative contents at $25^{\circ} \mathrm{C}$. As shown, there were wide differences in the type of compounds extracted and their proportions. The main volatile compounds present in UB of B. oldhamii were benzenoids (40.09\%), fatty acid (27.94\%), and $n$-alkanes $(11.21 \%)$. In contrast, the compounds found in $\mathrm{AB}$ of $B$. oldhamii were nitrogen compounds (30.41\%), aliphatic aldehyde (16.31\%), furan (13.17\%), aliphatic alcohol (12.37\%), and benzenoids (11.44\%). It is noticeable that aliphatic alcohol, aliphatic aldehyde, and furan were present in $\mathrm{AB}$ only. Comparatively, UB had remarkably more benzenoids than their $\mathrm{AB}$ counterparts $(40.09 \%$ vs. $11.44 \%$, respectively); while $\mathrm{AB}$ had considerably more nitrogen compounds than their UB counterparts (30.41\% vs. $10.15 \%$, respectively).

After SPME, 6 and 11 volatile compounds were identified from UB and AB of $B$. oldhamii, respectively at $25^{\circ} \mathrm{C}$ (Table 1 ). In other words, UB comprised fewer volatile compounds than AB. As indicated in Table 1, the primary volatile compounds found in UB were methyl salicylate $(38.91 \%)$, followed by $n$-hexadecanoic acid $(27.94 \%)$, and methoxy-phenyl oxime $(10.15 \%)$. In contrast, $\mathrm{AB}$ comprised mainly methoxy-phenyl oxime (30.41\%), followed by trans-2-nonenal (16.31\%), and 2-pentyl furan (13.17\%). Methoxy-phenyl oxime is the volatile compound found in abundance in both UB and AB of B. oldhamii. Zhang et al. (2010) investigated the impact of seafood storage methods on their volatile compound contents and found that fresh shrimps and crabs contained substantial amount of methoxy-phenyl oxime, which gives their distinct smell. Though of much smaller relative contents, limonene is another volatile compound found in both UB $(1.94 \%)$ and $\mathrm{AB}(3.99 \%)$. As shown in Table 2, limonene possesses a distinctive scent (Tu et al. 2002; Choi 2006; Gürbüz et al. 2006; Costa et al. 2008), which Ibrahim et al. (2001) found suitable for external use on pets as parasitic insecticide. In addition to its activity against insects and mites, limonene also has mosquito-repellent and antibacterial properties. Thus, limonene is an ingredient often utilized in natural agents against bacteria and insect pests. Despite being a natural enemy of pests, several cases have also shown phytotoxic effect of limonene on plants (Fagodia et al. 2017; Ibáñez et al. 2020), which also merits attention.

Methyl salicylate, a benzenoid compound, is present only in UB but absent in AB. Wang et al. (2008) reported that methyl salicylate has the scent of mint. In their study on food storage of African cultures, Jayasekara et al. (2002) found that root bark from Securidaca longepedunculata Fers (Polygalaceae), which comprises mainly methyl salicaylate (90\%), exhibited insect-repelling property. Moreover, Jao (2000) examined hydrogen cyanide levels of bamboo shoots used as food and reported conversion of some hydrogen compounds within bamboo shoots into cyanogenic glycoside. A commonly found compound in shoots of D. latiflorus and B. oldhamii is cyanogenic glycoside, which is toxic when consumed by animals at room temperature, revealing a form of defense mechanism adopted by plants. Similarly, the high relative content of methyl salicylate (38.91\%) in UB offers protection against bacteria and insects. The UB of B. oldhamii contains abundant carbohydrates; hence, to ensure continuous plant growth, its self-defense mechanisms involve not only forming a hard outer sheath, but also converting methyl salicylate into a natural insect repellent. In contrast, three aromatic volatile compounds, namely 2-pentyl furan, 1-octen-3-ol, and benzaldehyde, were found only in AB but were 
absent in UB. Figure 2 displays the chemical structure of major volatile compounds identified and Table 2 lists their distinctive aromas as reported in related literature.

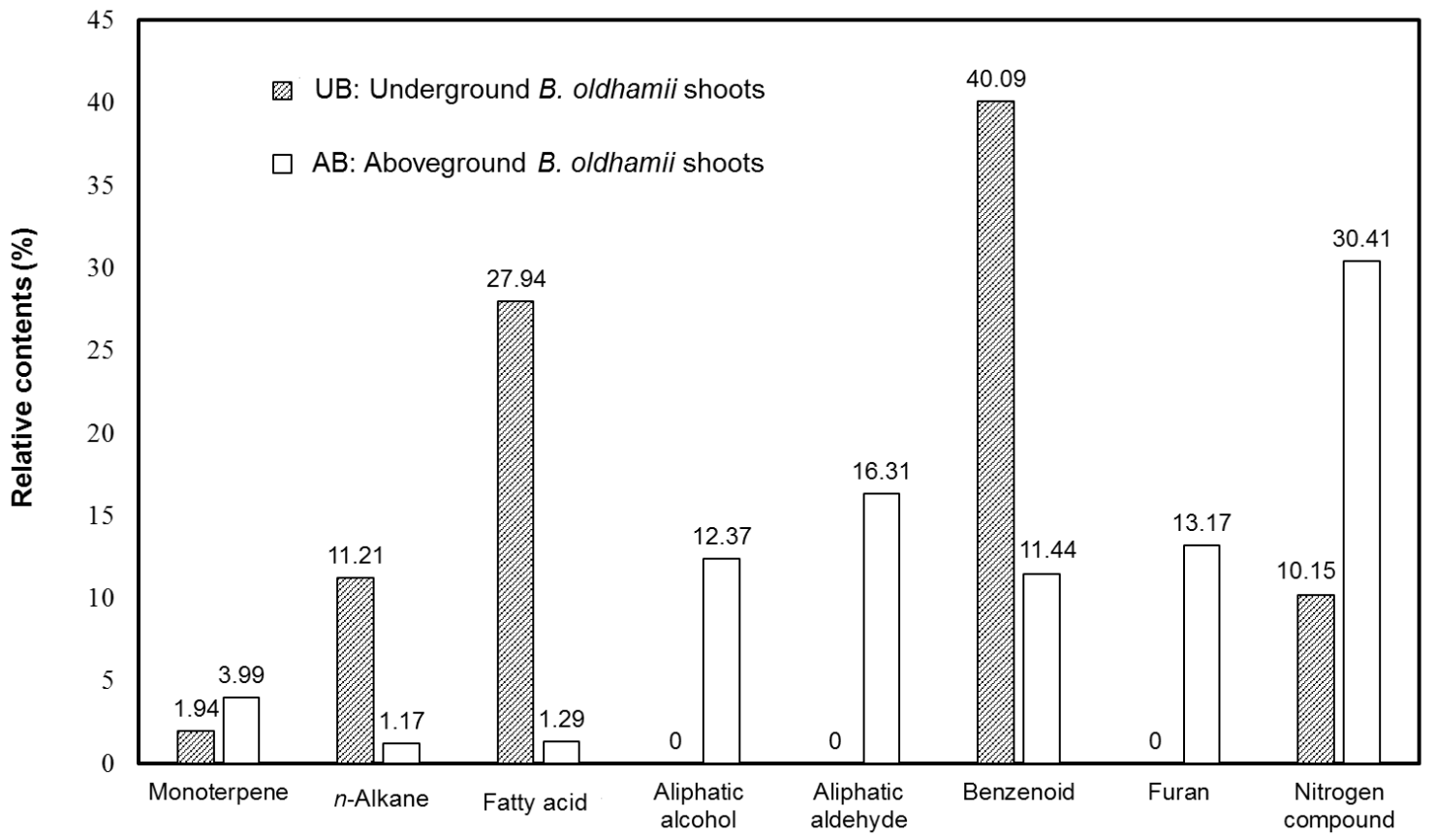

Fig. 1. Classes of volatile aromatic compounds present in B. oldhamii shoots at $25^{\circ} \mathrm{C}$

Table 1. Volatile Compounds Released from B. oldhamii Shoots at $25^{\circ} \mathrm{C}$

\begin{tabular}{|c|c|c|c|c|c|c|c|}
\hline \multirow[t]{2}{*}{ No. } & \multirow{2}{*}{$\begin{array}{c}\mathrm{RT} \\
(\mathrm{min})\end{array}$} & \multirow{2}{*}{$\mathrm{KI}^{\mathrm{a}}$} & \multirow{2}{*}{$r \mathrm{~K} \mathrm{l}^{\mathrm{b}}$} & \multirow{2}{*}{ Compounds } & \multicolumn{2}{|c|}{$\begin{array}{c}\text { Relative Content } \\
(\%)\end{array}$} & \multirow{2}{*}{ Identification ${ }^{\mathrm{e}}$} \\
\hline & & & & & $\mathrm{UB}^{\mathrm{c}}$ & $A^{d}$ & \\
\hline 1 & 9.80 & 901 & & Methoxy-phenyl oxime & 10.15 & 30.41 & MS \\
\hline 2 & 12.21 & 963 & 960 & Benzaldehyde & & 2.07 & $\mathrm{MS}, \mathrm{KI}, \mathrm{ST}$ \\
\hline 3 & 13.07 & 983 & 979 & 1-Octen-3-ol & & 2.45 & $\mathrm{MS}, \mathrm{KI}, \mathrm{ST}$ \\
\hline 4 & 13.44 & 991 & 988 & 2-Pentyl furan & & 13.17 & $\mathrm{MS}, \mathrm{KI}, \mathrm{ST}$ \\
\hline 5 & 15.03 & 1031 & 1029 & Limonene & 1.94 & 3.99 & $\mathrm{MS}, \mathrm{KI}, \mathrm{ST}$ \\
\hline 6 & 19.87 & 1155 & 1153 & cis-3-Nonen-1-ol & & 2.11 & $\mathrm{MS}, \mathrm{KI}, \mathrm{ST}$ \\
\hline 7 & 20.13 & 1162 & 1161 & trans-2-Nonenal & & 16.31 & $\mathrm{MS}, \mathrm{KI}, \mathrm{ST}$ \\
\hline 8 & 20.42 & 1170 & 1166 & cis-2-Nonen-1-ol & & 7.81 & MS, KI, ST \\
\hline 9 & 21.27 & 1191 & 1195 & Methyl salicylate & 38.91 & & $\mathrm{MS}, \mathrm{KI}, \mathrm{ST}$ \\
\hline 10 & 27.13 & 1358 & 1355 & 4-Hydroxybenzaldehyde & & 9.37 & $\mathrm{MS}, \mathrm{KI}, \mathrm{ST}$ \\
\hline 11 & 42.39 & 1961 & 1963 & $n$-Hexadecanoic acid & 27.94 & 1.29 & $\mathrm{MS}, \mathrm{KI}$ \\
\hline 12 & 43.98 & 2099 & 2100 & $n$-Heneicosane & 5.45 & 1.17 & $\mathrm{MS}, \mathrm{KI}, \mathrm{ST}$ \\
\hline 13 & 45.41 & 2199 & 2200 & $n$-Docosane & 5.76 & & $\mathrm{MS}, \mathrm{KI}, \mathrm{ST}$ \\
\hline & & & & Identified compounds (\%) & 91.33 & 90.13 & \\
\hline
\end{tabular}

RT: Retention time

${ }^{a}$ Kovats index relative to $\mathrm{C}_{9}$ to $\mathrm{C}_{22} n$-alkanes on the DB-5ms column;

${ }^{b}$ Identification through comparison of mass spectrum, Kovats index on a DB-5ms column in Adams (2007) and co-injection with authentic compounds;

c Underground B. oldhamii shoots;

d Aboveground B. oldhamii shoots;

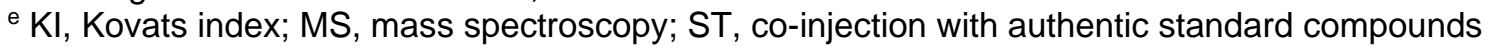


Table 2. Characteristic Odors of Volatiles in B. oldhamii Shoots at $25^{\circ} \mathrm{C}$

\begin{tabular}{|c|c|c|c|}
\hline No. & $\begin{array}{c}\text { Volatile } \\
\text { Compounds }\end{array}$ & Odor Descriptions & References \\
\hline 1 & $\begin{array}{c}\text { Methoxy-phenyl } \\
\text { oxime }\end{array}$ & $\begin{array}{c}\text { Fresh seafood, } \\
\text { fresh prawn or crab }\end{array}$ & Zhang et al. 2010 \\
\hline 2 & Limonene & $\begin{array}{c}\text { Citrus-like, pungent, lemon- } \\
\text { like, citric, fresh }\end{array}$ & $\begin{array}{c}\text { Tu et al. 2002; Choi 2006; Gürbüz et al. } \\
\text { 2006; Costa et al. 2008; Ibáñez et al. 2020 }\end{array}$ \\
\hline 3 & Methyl salicylate & Sweet, spicy, minty & Wang et al. 2008 \\
\hline 4 & 2-Pentyl furan & $\begin{array}{c}\text { Floral, fruit, cucumber, hay, } \\
\text { licorice, fatty (very faint), } \\
\text { meat broth, savory }\end{array}$ & $\begin{array}{c}\text { Klensporf and Henryk 2008; Yang et al. } \\
\text { 2008; Thompson et al. 2009; Olivares et } \\
\text { al. 2011 }\end{array}$ \\
\hline 5 & 1-Octen-3-ol & Mushroom smell & Toshiyuk et al. 2010 \\
\hline 6 & Benzaldehyde & $\begin{array}{c}\text { Almond, sweet, candy, } \\
\text { fruity, nutty, fragrant }\end{array}$ & $\begin{array}{c}\text { Gocmen et al. 2004; Costa et al. 2008; } \\
\text { Wang et al. 2008; Yang et al. 2008 }\end{array}$ \\
\hline
\end{tabular}<smiles>CCCCCC=CC=O</smiles>

trans-2-Nonenal<smiles>CCCCCc1ccco1</smiles>

2-Pentyl furan<smiles>CCCCCCCCCCCCCCCC(=O)O</smiles>

n-Hexadecanoic acid<smiles>COC(=O)c1ccccc1O</smiles>

Methyl salicylate<smiles>CCCCCCCCCCCCCCCCCCCCC</smiles><smiles>C=C(C)C1CC=C(C)CC1</smiles>

Limonene

Benzaldehyde<smiles>O=Cc1ccccc1</smiles>

4-Hydroxybenzaldehyde<smiles>C=CC(O)CCCCC</smiles>

1-Octen-3-ol<smiles>CCCCC/C=C/CCO</smiles><smiles>CCCCCCCCCCCCC</smiles>

Fig. 2. Chemical structures of major volatile compounds from B. oldhamii shoots 


\section{Effect of Heating Temperature on Volatile Compounds of B. oldhamii Shoots}

To investigate the impact of heating temperature on volatile compounds present in $\mathrm{UB}$ and $\mathrm{AB}$, approximately $3-\mathrm{g}$ samples were put into $20-\mathrm{mL}$ test bottles. Each sample was heated at 40,60 , and $100{ }^{\circ} \mathrm{C}$ for $30 \mathrm{~min}$. Figure 3 shows the volatile aromatic compounds present in the bamboo shoots analyzed using SPME. As shown, at ambient temperature (25 ${ }^{\circ} \mathrm{C}$ ), UB comprised predominantly benzenoids (40.09\%), followed by fatty acids (27.94\%), and $n$-alkanes $(11.21 \%)$. After heating at $40{ }^{\circ} \mathrm{C}$ for $30 \mathrm{~min}$, benzenoids clearly increased in relative content, reaching $66.29 \%$. However, further increase in heating temperature did not lead to higher relative contents of benzenoids. Instead, upon heating at $100^{\circ} \mathrm{C}$, the main volatile compounds present in UB became fatty acids (46.97\%), followed by $n$-alkanes (13.60\%), and aliphatic aldehyde (7.18\%).
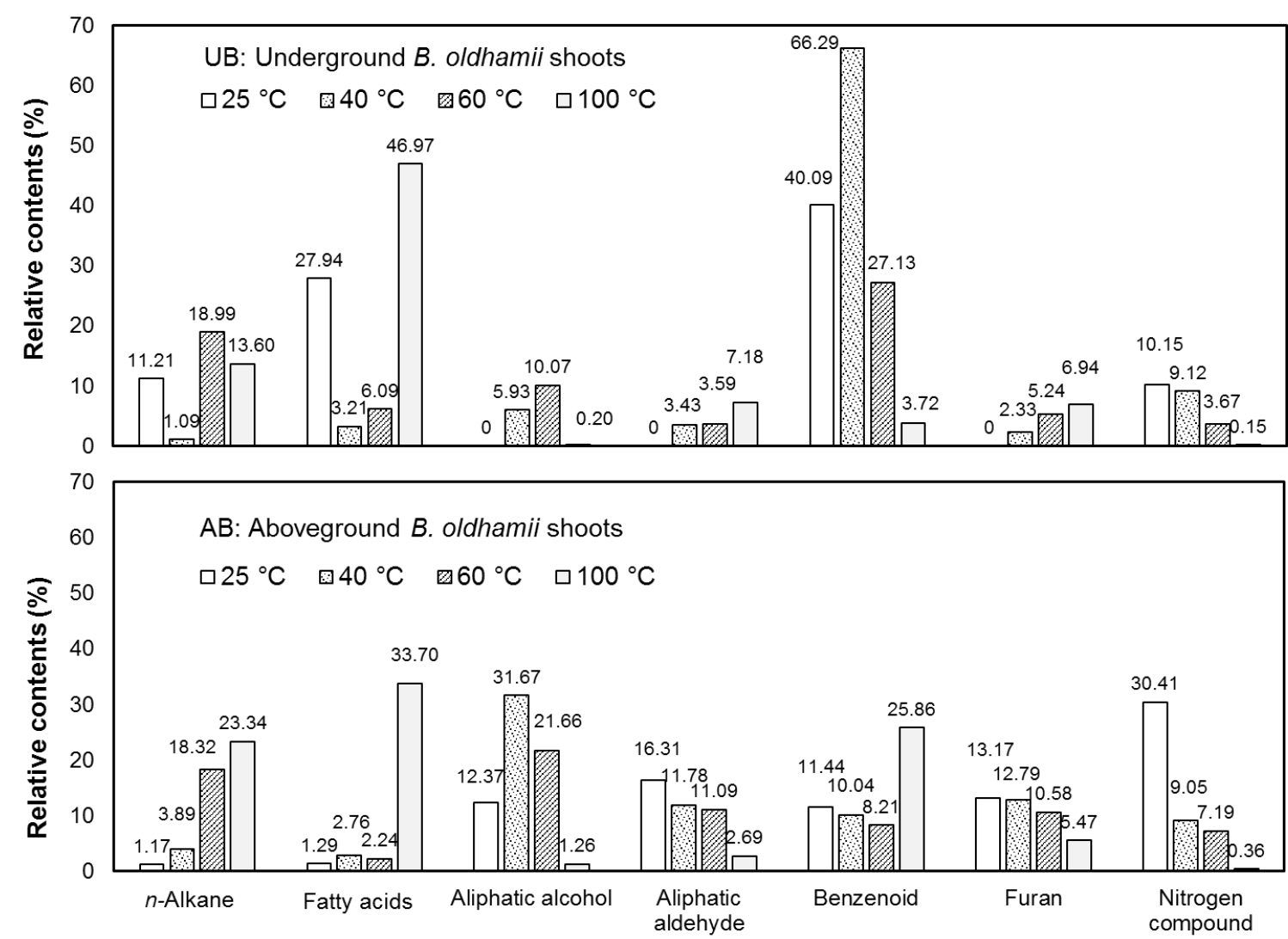

Fig. 3. Relative contents of volatile compounds present in $B$. oldhamii shoots heated at different temperatures for $30 \mathrm{~min}$

In contrast, $\mathrm{AB}$ at ambient temperature comprise a higher proportion of nitrogen compounds (30.41\%), followed by aliphatic aldehyde (16.31\%), and furan (13.17\%). However, upon heating at $100{ }^{\circ} \mathrm{C}$, the content of nitrogen compounds dropped markedly to $0.36 \%$. A similar decrease in relative content, though of a smaller extent, was also found in aliphatic aldehyde (2.69\%), furan (5.47\%), and aliphatic alcohol (1.26\%). In contrast, when heated at $100{ }^{\circ} \mathrm{C}$, fatty acids in $\mathrm{AB}$ showed a remarkable increase in relative content from $1.29 \%$ to $33.70 \%$. Likewise, after heating at $100{ }^{\circ} \mathrm{C}$, the relative content of $n$-alkanes rose from $1.17 \%$ at $25{ }^{\circ} \mathrm{C}$ to $23.34 \%$ while that of benzenoids, from $11.44 \%$ to $25.86 \%$. 
Hence, the three predominant volatile compounds in $\mathrm{AB}$ at ambient temperature and after heating at $100{ }^{\circ} \mathrm{C}$ were completely different.

Taken together, changes in relative content of volatile compounds at various heating temperatures evidenced remarkable impact of heating temperature on chemical composition of UB and $\mathrm{AB}$. Heating at any temperature reduced nitrogen compounds in $B$. oldhamii shoots, with a larger reduction observed in $\mathrm{AB}$. Contrasting trends were observed in furan and aliphatic aldehyde; their relative contents in UB increased with heating temperature but decreased in AB. Finally, both UB and $\mathrm{AB}$ when heated at $100{ }^{\circ} \mathrm{C}$ comprised mainly of fatty acids, followed by benzenoids, and $n$-alkanes.

Table 3 lists the major volatile compounds identified in B. oldhamii shoots heated at different temperatures for $30 \mathrm{~min}$. At $25^{\circ} \mathrm{C}$, benzenoids were predominant in UB, with methyl salicylate being the main compound (38.91\%). It remained the primary benzenoid compound even at higher heating temperatures of 40 and $60{ }^{\circ} \mathrm{C}$, though its relative content first increased $(68.60 \%)$, then decreased $(25.96 \%)$, and eventually it became non-existent at $100{ }^{\circ} \mathrm{C}$. In contrast, when heated at $100{ }^{\circ} \mathrm{C}$, both UB and $\mathrm{AB}$ comprised predominantly of fatty acids, with $n$-hexadecanoic acid ( $46.97 \%$ and $33.70 \%$, respectively) being the main compound. As mentioned above, the second predominant compound in UB heated at 100 ${ }^{\circ} \mathrm{C}$ was $n$-alkanes, primarily $n$-heneicosane (10.94\%). In contrast, apart from fatty acids, $\mathrm{AB}$ heated at $100{ }^{\circ} \mathrm{C}$ comprised benzenoids, with 4-hydroxybenzaldehyde (25.45\%) as the main compound, followed by $n$-alkanes, again primarily $n$-heneicosane $(21.88 \%)$.

Table 3. Changes in Relative Contents of Major Compounds of B. oldhamii Shoots Heated at Different Temperatures for $30 \mathrm{~min}$

\begin{tabular}{|c|c|c|c|c|c|c|c|c|}
\hline \multirow{2}{*}{ Compounds } & \multicolumn{2}{|c|}{$25^{\circ} \mathrm{C}$} & \multicolumn{2}{c|}{$40^{\circ} \mathrm{C}$} & \multicolumn{2}{c|}{$60^{\circ} \mathrm{C}$} & \multicolumn{2}{c|}{$100{ }^{\circ} \mathrm{C}$} \\
\cline { 2 - 9 } & UB & AB & UB & AB & UB & AB & UB & AB \\
\hline Methoxy-phenyl oxime & 10.15 & 30.41 & 9.12 & 9.05 & 3.67 & 7.19 & & 0.31 \\
\hline 2-Pentyl furan & & 13.17 & 2.33 & 12.79 & 5.24 & 9.68 & 6.94 & 5.03 \\
\hline trans-2-Nonenal & & 16.31 & & 11.78 & & 9.12 & & 1.66 \\
\hline cis-2-Nonen-1-ol & & 7.81 & 2.36 & 27.00 & 5.46 & 18.36 & & 0.97 \\
\hline Methyl salicylate & 38.91 & & 68.60 & & 25.96 & 0.53 & & \\
\hline 4-Hydroxybenzaldehyde & & 9.37 & & 5.77 & 1.18 & 5.12 & 3.07 & 25.45 \\
\hline$n$-Hexadecanoic acid & 27.94 & 1.29 & 3.21 & 2.76 & 6.09 & 2.24 & 46.97 & 33.70 \\
\hline$n$-Heneicosane & 5.45 & 1.17 & 1.09 & 3.89 & 13.74 & 14.40 & 10.94 & 21.88 \\
\hline
\end{tabular}

UB: Underground $B$. oldhamii shoots

$A B$ : Aboveground B. oldhamii shoots

Among the compounds listed in Table 3, a notable point was that 4hydroxybenzaldehyde in $\mathrm{AB}$ exhibited the most obvious increase in relative content from $9.37 \%$ at ambient temperature to $25.45 \%$ after being heated at $100{ }^{\circ} \mathrm{C}$. 4Hydroxybenzaldehyde, a compound identified in the extract of traditional Chinese medicine ingredient Gastrodia elata, suppresses monoamine oxidase (MAO), which was found to help ameliorate depression (Chen 2008). Moreover, Ha et al. (2000) identified 4hydroxybenzaldehyde in the ether fraction of $G$. elata methanol extract. The antiepileptic and anticonvulsive activity of $G$. elata B1 can be partially attributed to the antioxidation property of 4-hydroxybenzaldehyde and its neuromodulation effect. Hence, besides being 
high in dietary fiber, cooking bamboo shoots to high temperature can also bring additional health benefits.

\section{Effect of Heating Duration on Volatile Compounds of B. oldhamii Shoots}

Figure 4 displays the volatile aromatic compounds present in bamboo shoots steamed at $100{ }^{\circ} \mathrm{C}$ for 5,30 , and $60 \mathrm{~min}$. Contrasting trends are seen with respect to changes in relative contents of compounds analyzed using SPME. As shown, contents of fatty acids in UB increased with heating duration, rising remarkably from $4.49 \%$ at 5 min to $46.97 \%$ at $30 \mathrm{~min}$, and reaching $68.68 \%$ at $60 \mathrm{~min}$. Longer heating duration yielded the predominant compound present in UB. The same linear relationship was also observed for fatty acids in $\mathrm{AB}$, increasing markedly from $7.34 \%$ at $5 \mathrm{~min}$ to $33.70 \%$ at $30 \mathrm{~min}$, and reaching $45.49 \%$ at $60 \mathrm{~min}$. Similarly, upon being heated for longer durations, its relative content increased in the main volatile compounds from $\mathrm{AB}$.
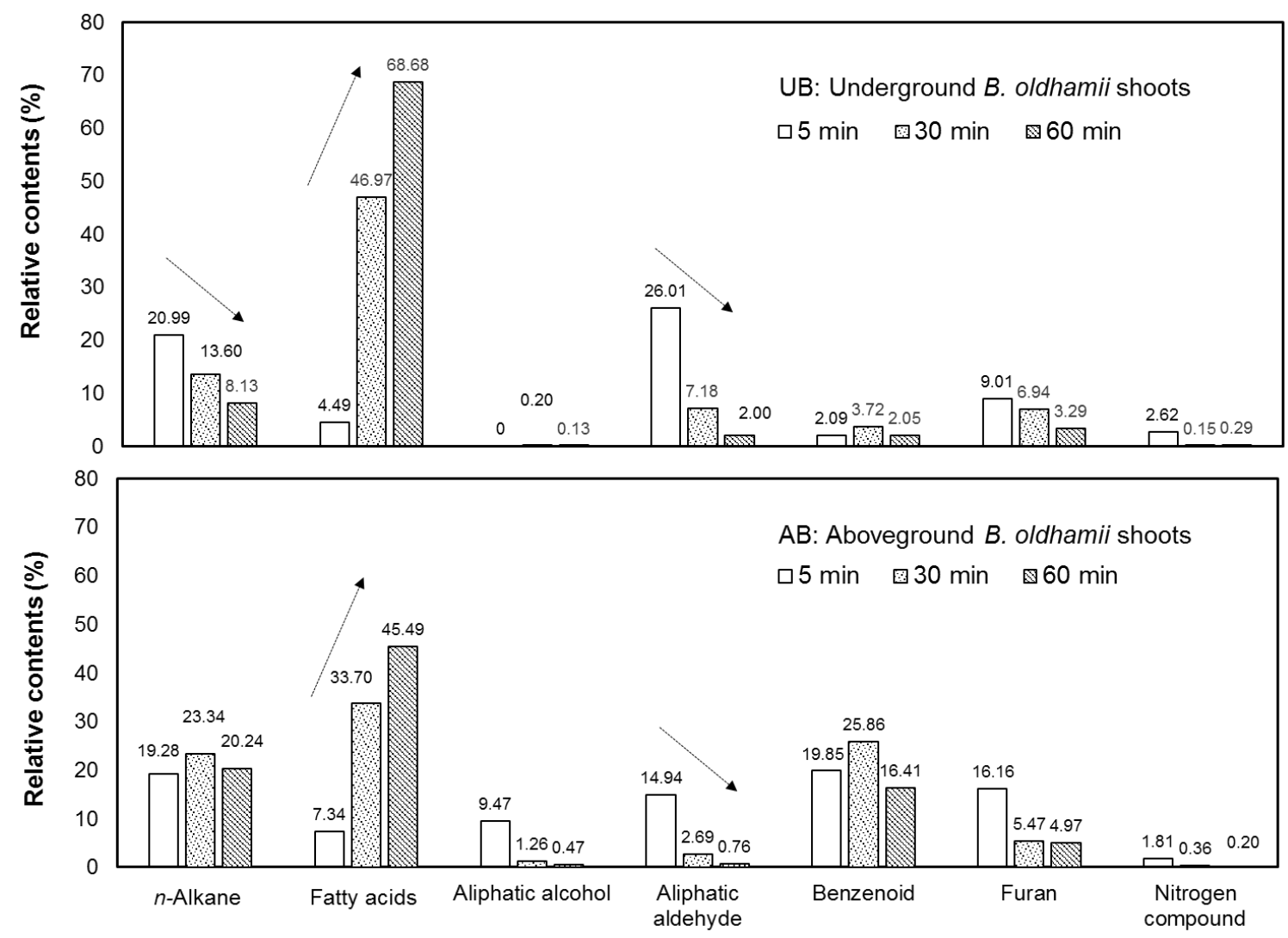

Fig. 4. Relative contents of volatile compounds present in B. oldhamii bamboo shoots heated at $100{ }^{\circ} \mathrm{C}$ for different durations

In contrast, aliphatic aldehyde, $n$-alkanes, and furan contents in UB showed an inverse relationship between relative content and heating duration. Thus, the longer the shoots are heated, the relative contents of these volatile compounds were decreased. As shown, after heating at $5 \mathrm{~min}$, aliphatic aldehyde (26.01\%) was the predominant compound, followed by $n$-alkanes $(20.99 \%)$ and furan $(9.01 \%)$. Further heating reduced their relative contents to $7.18 \%, 13.60 \%$, and $6.94 \%$, respectively, at $30 \mathrm{~min}$. After 30 -min heating, the fatty acids $(46.97 \%)$ content replaced $n$-alkanes as the main component, followed by aliphatic aldehyde. After 60 -min heating, the relative content of aliphatic 
aldehyde and $n$-alkanes dropped considerably from their initial high levels to only $2.00 \%$ and $8.13 \%$, respectively. The same inverse relationship was observed only for aliphatic aldehyde and furan, but not for $n$-alkanes in AB. The relative contents of aliphatic aldehyde and furan dropped respectively from $14.94 \%$ and $16.16 \%$ after 5-min heating to $2.69 \%$ and $5.47 \%$ after 30 -min heating, respectively.

Moreover, notable variation in relative contents of benzenoids present in UB and AB was observed. The UB comprised only $2.09 \%, 3.72 \%$, and $2.05 \%$ of benzenoids after being heated for $5 \mathrm{~min}, 30 \mathrm{~min}$, and $60 \mathrm{~min}$, respectively; while $\mathrm{AB}$ contained $19.85 \%$, $25.86 \%$, and $16.41 \%$, respectively. Despite the wide differences in relative contents, they showed the same trend of changes with heating periods; that is, first increased, then decreased.

Only traces of nitrogen compounds and aliphatic alcohol were present in UB and $\mathrm{AB}$ when heated at $100{ }^{\circ} \mathrm{C}$ and their relative contents reduced even further after 60 -min heating. Taken together, the analysis results revealed variations in trend of changes and relative contents in $\mathrm{UB}$ and $\mathrm{AB}$ heated for different durations. After 5-min heating at 100 ${ }^{\circ} \mathrm{C}$, the predominant compound was aliphatic aldehyde in UB and benzenoids in AB. Upon further heating, more fatty acids were formed and it became the main compounds in both types of shoots.

Table 4 lists the major volatile compounds identified in B. oldhamii shoots heated at $100{ }^{\circ} \mathrm{C}$ for various time intervals.

Table 4. Changes in Relative Contents of Major Compounds of $B$. oldhamii Bamboo Shoots Heated at $100{ }^{\circ} \mathrm{C}$ for Different Durations

\begin{tabular}{|c|c|c|c|c|c|c|}
\hline \multirow{2}{*}{ Compounds } & \multicolumn{2}{|c|}{$5 \mathrm{~min}$} & \multicolumn{2}{c|}{$30 \mathrm{~min}$} & \multicolumn{2}{c|}{$60 \mathrm{~min}$} \\
\cline { 2 - 7 } & UB & $\mathrm{AB}$ & $\mathrm{UB}$ & $\mathrm{AB}$ & UB & $\mathrm{AB}$ \\
\hline$n$-Hexanal & 7.44 & 0.93 & 1.60 & 0.31 & 0.53 & 0.11 \\
\hline Methoxy-phenyl oxime & 2.62 & 1.81 & & 0.31 & 0.21 & 0.17 \\
\hline 2-Pentyl furan & 9.01 & 14.82 & 6.94 & 5.03 & 3.29 & 3.78 \\
\hline trans-2-Nonenal & & 12.52 & & 1.66 & & 0.48 \\
\hline cis-2-Nonen-1-ol & & 6.94 & & 0.97 & & 0.36 \\
\hline (2E,4E)-Decadienal & 16.95 & 1.01 & 5.07 & 0.47 & 1.28 & 0.09 \\
\hline 4-Hydroxybenzaldehyde & & 18.33 & 3.07 & 25.45 & 1.62 & 16.17 \\
\hline$n$-Hexadecanoic acid & 4.49 & 7.34 & 46.97 & 33.70 & 68.68 & 45.49 \\
\hline$n$-Heneicosane & 12.76 & 19.28 & 10.94 & 21.88 & 6.47 & 18.67 \\
\hline$n$-Docosane & 8.23 & & 1.76 & 1.46 & 1.24 & 1.57 \\
\hline
\end{tabular}

UB: Underground $B$. oldhamii shoots

$A B$ : Aboveground $B$. oldhamii shoots

As shown, the number of volatile compounds present in the shoots varied with heating period. In general, more volatile compounds were found with longer heating duration. In UB, 7 compounds were identified after heating for $5 \mathrm{~min}$ and $30 \mathrm{~min}$, but 8 compounds after 60-min heating. Important observation is that the 7 compounds identified after 5- and 30-min heating periods were not the same. Methoxy-phenyl oxime was observed after 5-min heating, which disappeared after 30-min heating but reappeared after 
60-min though in traces. In $\mathrm{AB}$, more compounds were identified, 9, 10, and 10 different compounds after heating for $5 \mathrm{~min}, 30 \mathrm{~min}$, and $60 \mathrm{~min}$, respectively. In other words, AB comprised more volatile compounds than UB. Specifically, trans-2-nonenal and cis-2nonen-1-ol were found only in AB but not in UB.

Consistent with the results displayed in Fig. 4, $n$-hexadecanoic acid was the predominant fatty acid compound, and its relative content in both $\mathrm{UB}$ and $\mathrm{AB}$ increased with increasing heating periods. In contrast, $(2 E, 4 E)$-decadienal was the main aliphatic aldehyde compound, with relative contents in both UB and $A B$ decreasing with heating duration. For benzenoids, 4-hydroxybenzaldehyde was the main compound in AB, whose relative content first increased after heating for $30 \mathrm{~min}$, but decreased with further heating for $60 \mathrm{~min}$. These outcomes align with the investigation of Chung et al. (2012) that examine the impacts on the volatile compounds in moso bamboo shoots from both spring and winter after steaming.

\section{CONCLUSIONS}

This research focused on using solid-phase microextraction (SPME) to extract volatile compounds from $\mathrm{UB}$ and $\mathrm{AB}$ of $B$. oldhamii and then using gas chromatographymass spectrometry (GC-MS) to analyze the extracts at ambient temperature and heating for various time periods.

1. At ambient temperature, both underground types of bamboo shoots mainly hold volatile compounds with distinctive scents: $38.91 \%$ of methyl salicylate that has the sweet minty fragrance and minty and $30.41 \%$ of a nitrogen compound known as methoxy-phenyl oxime, which holds a scent akin to fresh shrimp and crabs.

2. Both underground bamboo shoots (UB) and aboveground bamboo shoots (AB) when heated at $100{ }^{\circ} \mathrm{C}$ for 60 min comprised mainly of fatty acids ( $n$-hexadecanoic acid), followed by $n$-alkanes ( $n$-heneicosane).

3. When $\mathrm{UB}$ and $\mathrm{AB}$ of $\mathrm{B}$. oldhamii were heated at $100{ }^{\circ} \mathrm{C}$ for $30 \mathrm{~min}$, they mainly produced the fatty acid compound of $n$-hexadecanoic acid at $46.97 \%$ and $33.70 \%$, respectively.

\section{ACKNOWLEDGEMENTS}

This study was supported by a Grant (109-C02) from the Experimental Forest, College of Bioresource and Agriculture, National Taiwan University, Taiwan, ROC. The authors also thank the Forestry Bureau for financial support.

\section{REFERENCES CITED}

Adams, R. P. (2007). Identification of Essential Oil Components by Gas Chromatography and Mass Spectroscopy, Allured Publishing Corporation, Carol Stream, IL, USA.

Chen, P. J., Hsieh, C. L., Su, K. P., Hou, Y. C. Chiang, H. M., Lin, I. H., and Sheen, L. 
Y. (2008). "The antidepressant effect of Gastrodia elata Bl. on the forced-swimming test in rats," The American Journal of Chinese Medicine 36(1), 95-106. DOI: 10.1142/S0192415X08005618

Chen, Y. J., Cheng, S. S., and Chang, S. T. (2010). "Monitoring the emission of volatile organic compounds from the leaves of Calocedrus macrolepis var. formosana using solid-phase micro-extraction," Journal of Wood Science 56, 140-147. DOI: $10.1007 / \mathrm{s} 10086-009-1071-\mathrm{z}$

Choi, H. S. (2006). "Headspace analyses of fresh leaves and stems of Angelica gigas Nakai, a Korean medicinal herb," Flavour and Fragrance Journal 21(4), 604-608. DOI: $10.1002 / f f j .1602$

Chung, M. J., Cheng, S. S., Lin, C. Y., and Chang, S. T. (2012). "Profiling of volatile compounds of Phyllostachys pubescens shoots in Taiwan," Food Chemistry 134(4), 1732-1737. DOI: 10.1016/j.foodchem.2012.03.120

Costa, R., Zellner, B. A., Crupi, M. L., De Fina, M. R., Valentino, M. R., Dugo, P., Dugo, G., and Mondello, L. (2008). "GC-MS, GC-O and enantio-GC investigation of the essential oil of Tarchonanthus camphoratus L," Flavour and Fragrance Journal 23(1), 40-48. DOI: 10.1002/ffj.1854

Cui, F. X., Ding, X. C., Li, L. S., Zhang, Z. Y., and Cai, H. J. (2017). "Relationship between types and contents of flavour substances and spicy intensity in moso bamboo (Phyllostachys edulis) shoots," Forest Research 30, 1041-1049. DOI: 10.13275/j.cnki.lykxyj.

Fagodia, S. K., Singh, H. P., Batish, D. R., and Kohli, R. K. (2017). "Phytotoxicity and cytotoxicity of Citrus aurantiifolia essential oil and its major constituents: Limonene and citral," Industrial Crops and Products 108(1), 708-715. DOI: 10.1016/j.indcrop.2017.07.005

Fu, S. G., Yoon, Y., and Bazemore, R. (2002). "Aroma-active components in fermented bamboo shoots," Journal of Agriculture and Food Chemistry 50(3), 549-554. DOI: 10.1021/jf010883t

Gocmen, D., Gurbuz, O., Rouseff, R. L., Smoot, J. M., and Dagdelen, A. F. (2004). "Gas chromatographic-olfactometric characterization of aroma active compounds in sundried and vacuum-dried tarhana," European Food Research and Technology 218, 513-578. DOI: 10.1007/s00217-004-0913-6

Gürbüz, O., Rouseff, J. M., and Rouseff, R. L. (2006). “Comparison of aroma volatiles in commercial Merlot and Cabernet sauvignon wines using gas chromatographyolfactometry and gas chromatography-mass spectrometry," Journal of Agriculture and Food Chemistry 54(11), 3990-3996. DOI: 10.1021/jf053278p

Ha, J. H., Lee, D. U., Lee, J. T., Kim, J. S., Yong, C. S., Kim, J. A., Ha, J. S., and Huh, K. (2000). "4-Hydroxybenzaldehyde from Gastrodia elata B1 is active in the antioxidation and GABAergic neuromodulation of the rat brain," Journal of Ethnopharmacology 73(1-2), 329-333. DOI: 10.1016/S0378-8741(00)00313-5

Ibáñez, M. D., Sanchez-Ballester, N. M., and Blázquez, M. A. (2020). "Encapsulated limonene: A pleasant lemon-like aroma with promising application in the agri-food industry. A review," Molecules 25(11), 2598-2618. DOI:

10.3390/molecules25112598

Ibrahim, M. A., Kainulainen, P., and Aflatuni, A. (2001). "Insecticidal, repellent, antimicrobial activity and phytotoxicity of essential oils: With special reference to limonene and its suitability for control of insect pests," Agricultural and Food Science 10(3), 243-259. DOI: 10.23986/afsci.5697 
Jao, M. L. (2000). Studies on Analysis of Hydrogen Cyanide in the Bamboo Shoots, Master's Thesis, National Taiwan University, Taipei, Taiwan. (In Chinese)

Jayasekara, T. K., Stevenson, P. C., Belmain, S. R., Farman, D. I., and Hall, D. R. (2002). "Identification of methyl salicylate as the principal volatile component in the methanol extract of root bark of Securidaca longepedunculata Fers," Journal of Mass Spectrometry 37(6), 577-580. DOI: 10.1002/jms.314

Klensporf, D., and Henryk, H. J. (2008). "Effect of heat treatment on the flavor of oat flakes," Journal of Cereal Science 48(3), 656-661. DOI: 10.1016/j.jcs.2008.02.005

Liese, W. (1987). "Research on bamboo," Wood Science and Technology 21, 189-209.

Lu, B., Cai, H., Wu, X., Luo, Y., Liu, L., and Zhang, Y. (2011). "Protective effect of bamboo shoot oil on experimental nonbacterial prostatitis in rats," Food Chemistry 124(3), 1017-1023. DOI: 10.1016/j.foodchem.2010.07.066

Lu, C. M. (2001). Cultivation and Management of Bamboo Forests, Taiwan Forestry Research Institute Publisher, Taipei, Taiwan. (In Chinese)

Olivares, A., Navarro, J. L., and Flores, M. (2011). "Effect of fat content on aroma generation during processing of dry fermented sausages," Meat Science 87(3), 264273. DOI: $10.1016 /$ j.meatsci.2010.10.021

Park, E. J., and Jhon, D. Y. (2010). "The antioxidant, angiotensin converting enzyme inhibition activity, and phenolic compounds of bamboo shoot extracts," LWT - Food Science and Technology 43(4), 655-659. DOI: 10.1016/j.lwt.2009.11.005

Satya, S., Bal, L. M., Singhal, P., and Naik, S. N. (2010). "Bamboo shoot processing: Food quality and safety aspect (A review)," Trends in Food Science \& Technology 21(4), 181-189. DOI: 10.1016/j.tifs.2009.11.002

Steffen, A., and Pawliszyn, J. (1996). "Analysis of flavor volatiles using headspace solidphase microextraction," Journal of Agriculture and Food Chemistry 44(8), 21872193. DOI: $10.1021 /$ jf950727k

Thompson, A., Boland, M., and Singh, H. (2009). Milk Proteins: From Expression to Food, A Macmillan Company, New York City, NY, USA.

Tsai, S. W. (2002). The Antibacterial Activities of Various Species of Bamboo Shoot Extracts, Master's Thesis, National Pingtung University of Science and Technology, Neipu, Taiwan. (In Chinese)

Tu, N. T. M., Onishi, Y., Choi, H. S., Kondo, Y., Bassore, S. M., Ukeda, H., and Sawamura, M. (2002). "Characteristic odor components of Citrus sphaerocarpa Tanaka (Kabosu) cold-pressed peel oil," Journal of Agricultural and Food Chemistry 50(10), 2908-2913. DOI: 10.1021/jf011578a

Wang, L. F., Lee, J. Y., Chung, J. O., Baik, J. H., So, S., and Park, S. K. (2008). "Discrimination of teas with different degrees of fermentation by SPME-GC analysis of the characteristic volatile flavor compounds," Food Chemistry 109(1), 196-206. DOI: 10.1016/j.foodchem.2007.12.054

Yang, D. S., Lee, K. S., Jeong, O. Y., Kim, K. J., and Kays, S. J. (2008). "Characterization of volatile aroma compounds in cooked black rice," Journal of Agricultural and Food Chemistry 56(1), 235-240. DOI: 10.1021/jf072360c

Zhang, Z., Li, G., Lin, L., and Chen, G. (2010). "Study on seafood volatile profile characteristics during storage and its potential use for freshness evaluation by headspace solid phase microextraction coupled with gas chromatography-mass spectrometry," Analytica Chimica Acta 659(1-2), 151-158. DOI:

10.1016/j.aca.2009.11.024 
Zhang, Z. Y., Ding, X. C., Cui, F. X., and Cai, H. J. (2016). "Impact of avoiding light on bitterness and astringency, tannin content, morphology and distribution of Dendrocalamus latiflorus," Forest Research 29, 770-777.

Article submitted: February 25, 2021; Peer review completed: June 7, 2021; Revised version received and accepted: June 27, 2021; Published: July 12, 2021.

DOI: $10.15376 /$ biores.16.3.5901-5914 